\title{
Positional differences in anticipation timing, reaction time and dynamic balance of American football players
}

\author{
Halil İ. Ceylan ${ }^{1 \mathrm{ACB}}$, Ahmet R. Günay ${ }^{2 \mathrm{BE}}$ \\ ${ }^{1}$ Ataturk University, Erzurum, Turkey \\ ${ }^{2}$ Mugla Sitki Kocman University, Mugla, Turkey
}

Authors' Contribution: A - Study design; B - Data collection; C - Statistical analysis; D - Manuscript; Preparation; E - Funds Collection.

\begin{abstract}
Purpose:

The aim of this study was to compare the coinciding anticipation timing (CAT), reaction time and dynamic balance performances of American football players according to their playing positions.

Material:

Thirty-five American football players, who train at least 3 days a week, and compete in Universities Protected Football 1st League, participated in this study, voluntarily. The players were divided into two playing positions: offensive (17 players, mean age: $20.76 \pm 1.30$ years) and defensive (18 players, mean age: $21.94 \pm 2.87$ years). The CAT at different stimulus speeds $(6 \mathrm{mph}, 12 \mathrm{mph}$ ), reaction time (visual, auditory, mixed), and dynamic balance performance (anterior-posterior, medial-lateral, perimeter lenght) were measured in the laboratory environment. The CAT, reaction time, and dynamic balance performance of players were determined by Bassin Anticipation Timer, Newtest 1000, and Technobody Prokin-200, respectively.

Results: $\quad$ The data obtained were analyzed in SPSS (20.0) program. Firstly, the raw data for CAT performance $(6 \mathrm{mph}, 12 \mathrm{mph}$ ) were converted to absolute error score. According to Shapiro-Wilk test result, the all data showed normal distribution. Independent Sample t test was used to determine the differences between the two playing positions. In addition, the effect size between the two playing positions was calculated in parameters with showing significant differences, and Cohen's d (1988) values were taken into account. Compared with the defensive players $(20.15 \pm 3.81 \mathrm{~ms})$, the absolute error scores at fast stimulus speeds $(12 \mathrm{mph})$ of offensive players $(17.45 \pm 3.48 \mathrm{~ms})$ was found to be significantly lower $\left(t_{(33)}=-2.181, p=.036\right)$. The visual reaction time of offensive players $(318.11 \pm 17.47 \mathrm{~ms})$ was significantly shorter than defensive players $\left(340.58 \pm 32.60 \mathrm{~ms}, \mathrm{t}_{(26322)}=-2.560, \mathrm{p}=.017\right)$. In terms of dynamic balance parameters such as perimeter lenght, anterior-posterior, and medial-lateral, there was no statistically significant difference between the playing positions ( $p>0.05$ ).

Conclusions: $\quad$ Perceptual-cognitive characteristics such as CAT, and reaction time performance differ according to the playing positions, and this difference may be related to the physical, and cognitive demands required by their playing positions.

Keywords: $\quad$ american football, coinciding anticipation timing, dynamic balance, reaction time.
\end{abstract}

\section{Introduction}

American football is one of the most competitive, and popular team sports in the United States [1]. The game is played at the college level in National Collegiate Athletic Association (NCAA), and at the professional level in the National Football League(NFL) [2]. The NFL is the highest athletic competition level for American football, and competing in NFL requires exceptional skills and physical abilities [1]. American football is a crash-based sport including intense physical collisions, and characterized by intermittent short duration maximum high intensity activities separated by short rest times between games. It requires physical performance characteristics such power, strength, speed, acceleration, deceleration [2-6], and also skills such as catching, throwing, backpedalling, stealing, blocking, backpedalling, and back-pedaling, and sudden multi-directional running in-match performance [7]. The game is played by 11 players on each team. The playing positions are grouped into defensive (defensive backs, DB; linebackers, LB; defensive linemen, DL),

(c) Halil İ. Ceylan, Ahmet R. Günay, 2020

doi:10.15561/26649837.2020.0503 offensive quarterbacks, QB; running backs, RB; offensive linemen, OL; wide receivers, WR; halfbacks, $\mathrm{HB}$, and special (kickers, K; punters, P) players [8]. Each playing position has specific responsibilities, and the physical, physiological, biomechanical, and perceptual-cognitive demands of the game are quite different for players in different positions $[3,6,8,9]$. American football is played in a chaotic visual environment filled with relevant, and distracting information that negatively affects the response potential of the players [10]. Therefore, the ability to quickly and accurately predict or perceive relevant information within a limited time in a unpredictable environment facilitates sudden, fast and accurate decision-making, gives the player more time to prepare, and regulate their motor behaviors [11, 12]. Performing such actions in complex game sequences that are not previously determined involves high-level perceptualcognitive, and advanced sensorimotor characteristics [10, $13,14]$. These characteristics are CAT, reaction time, and balance performance.

According to Fleury \& Bard [15], CAT is the capacity to predict the approach of a moving object in a particular 
sign in space, and to synchronize the movement response with that arrival. In sports, because of the dynamic nature of the environment, and the fact that players need to display their activities in a limited time, CAT performance is very important, and forms the basis for high performance $[16,17,18]$. Elite athletes or players predict when and what will happen in the environment, and for this, they use various information processing activities before the stimulus [19]. They take all the necessary information from the postural, and kinematic cues resulting from the opponent's movement $[16,17$, 20], pattern recognition [21], direction, and speed of the ball [22] in the prediction process. CAT performance is also very important in Amerikan Football, and two kinds of anticipation can be mentioned. These; spatial and temporal anticipation. Spatial anticipation, the player receives information from the opponent about the content of the movement, and when it will take place, and then react to the movements in a very short time by taking the correct position. He organizes the movements in advance. In American football, defensive lineman knows which game is being played, and starts his movement simultaneously according to the game. The interception of ball in the air can be an example of temporal anticipation. In this anticipation type, despite having a strong clue about when the event will occur, being unable to predict what will happen prevents the player from organizing his action in advance [19]. In addition, players face situations in American Football that prevent them from predicting or 'reading' the situation. Such situations force the player to react after the event (due to the oval shape of the ball, the ball may bounce randomly, the bounce direction of the ball can be difficult to predict) [16].

The reaction time is defined as the minimum time between taking a sudden, and unexpected stimulus, and the reaction given to it [23]. In American football, having a short reaction time of the player is a critical component in terms of responding to the stimuli as quickly and accurately as possible, by choosing the relevant ones from many information in the chaotic visual field, and provides an advantage in games [24, 25]. Mankowska et al. [26] observed that an player's ability to quickly assess an opponent's position and direction is significantly related to response times. The offensive players such as wide receivers, running backs, and quarterbacks can make athletic moves in the opposite direction to distract defenders and cause slow their reaction times. Therefore, the fast and accurate response time of the defensive players should be very good against certain hints on the field, and especially the surprising movements of the offensive players, and also minimizing their reaction time as much as possible to increase the chances of successfully 'winning' a game is crucial to preventing offense or scoring [25]. Likewise, the reaction times of offensive players also need to be very short in order to successfully make sudden changes, and maneuvers with rapid movement of the limbs in the games, and to gain points [27].

Dynamic balance is the ability of the individual to maintain the stability of the center of mass during movements, and is important in American football as in many sports branches [28]. American football requires players to have unprecedented coordination, that is, dynamic balance ability, to deal with rapidly changing external conditions, complete complex multidirectional movements at high speed, and to succeed in blocking, catching, change of direction, and tackling under pressure or in contact with opposing players [29, 30]. Compared to other sports branches, injuries are very common in American football, and poor dynamic balance performance and increased swing are associated with a higher risk of injury. The NCAA reported that more than 3 million players suffered injuries as a result of the analysis of data from 3 NCAA leagues from 2004 to 2014 [31]. Due to the characteristic nature of the game, contact or collision with players is the primary cause of injuries, and injuries are mostly strains or sprains that affect the lower limbs $[32,33]$.

It was reported that each game lasts an average of $5.49 \mathrm{~s}$ (between 1.87 and $12.88 \mathrm{~s}$ ) at the college level, and in NFL, each game takes an average of $5.0 \mathrm{~s}$. [3]. This information shows that the game plays very fast, and ends in seconds. The players are exposed to collisions, and blunt force trauma as a result of frequent repeated contact with opponents, and the ground during tackling, blocking, and ball handling activities. This induces additional stress on players, which is not common in other forms of physical activity [34, 35]. Despite this stress, it is important that players have and maintain their high-level perceptual-cognitive functions, and advanced sensorimotor characteristics during the games to gain points, to advance the ball, to intercept injuries by preventing possible collisions with the opponents, to move quickly to empty spaces without colliding, and to throw the ball to their teammates at the right time by reading the game well. In the literature, there are some studies that evaluate the performance characteristics of American football players such as sprint and jump (9), match performance [35], running and non-running activities [2], impulse control [36], executing motor responses in the face of distraction [10], and impact profiles which they are exposed to [5] according to the their playing positions. There is limited study comparing the perceptual-cognitive, and sensorimotor characteristics of American football players such as CAT, reaction time, and dynamic balance performance by their playing positions. This reveals the importance of the study in terms of literature. In line with previous studies [37, 38], and considering the nature of American football, our first hypothesis was established that offensive players have better CAT, and reaction time performance than defensive players. The second hypothesis was that defensive players have superior dynamic balance performance than offensive players.

\section{Material and Methods \\ Participants}

Thirty-five volunteer American football players, who 
do not have any health problems, train at least 3 days a week, and compete in Universities Protected Football 1st League, participated in this study. Before the study, faceto-face interviews were held with the players about the purpose, importance, content, and methodical model of this study. The volunteers were determined to participate in the study, and Informed Consent Form was signed, and then the players were divided into two the playing positions: offensive (17 players; quarter backs, running backs, offensive linemen, receivers, mean age: $21.94 \pm$ 2.87 years), and defensive (18 players; defensive backs, line backers, defensive linemen, mean age: $20.76 \pm 1.30$ year)

\section{Research Design.}

Collection of Data

The measurements were carried out between 08.00-11.00 hours in Mugla Sitki, Kocman University Performance Laboratory. One day before the day of measurements, the players were informed about avoiding to perform exercise at high intensity, getting enough sleep (at least 10 hours), and not using substances such as alcohol, caffeine, and stimulants. On the measurement day, all players were present at the laboratory at 08:00 a.m. Firstly, the height and body weight of players were collected, and then their body fat percentage was calculated by Tanita. Then, the players were individually taken to a quiet, calm, and low-light environment, and their CAT performance were measured randomly at different stimulus speeds (6 $\mathrm{mph}$ and $12 \mathrm{mph}$ ). (Table 1). Visual (light), auditory (sound) and mixed (light or sound) reaction time measurements were performed after the CAT measurements in the same environment. After 15 minutes dynamic, and static warm-ups exercises [39], the dynamic balance performance of the players (anteriorposterior, medial-lateral) were determined using the Prokin 200 device.

Data Collection Tools

Heigh and body weight measurements: Th body weight of the players were determined by Seca (Germany) electronic scale with a sensitivity of $0.01 \mathrm{~kg}$, and their height were measured in bare feet, and standing upright position with a metal meter with a precision of $0.01 \mathrm{~cm}$, which is fixed in that scale [40].

Body fat percentage: Bioelectrical Impedance Analysis (Tanita TBF-401A device) method was utilized to detect the body fat percentage of the players. Before coming to the measurements, the players were informed about the criteria proposed by the American College of Sports Medicine [41] to minimize the error in the measurements. The players were asked to step on the four contact electrons mounted on the platform surface with bare feet, stand motionless, and upright until the results appear on the screen. The body fat percentage was calculated automatically with special equations preprogrammed by the manufacturer [42, 43].

CAT performance: The Bassin Anticipation Timer (Lafayette Instrument Company, Model 35575) was used for CAT measurements at different stimulation speeds (6 $\mathrm{mph}$ and $12 \mathrm{mph}$ ) of players. This device was developed by Stanley Bassin to assess the visual acuity area associated with hand eye coordination, and anticipation. In the literature, it was reported that this device is a valid, and reliable method used in the evaluation of CAT performance in the studies performed in different sports branches [37, 44, 45, 46, 47]. Rodrigues et al. [48] stated that $6 \mathrm{mph}(268 \mathrm{~cm} / \mathrm{s})$ stimulus speed as "slow", and 12 $\mathrm{mph}(536.4 \mathrm{~cm} / \mathrm{s})$ warning speed as "fast". Therefore, the criteria of Rodrigues et al. [48] were taken in choosing 6 $\mathrm{mph}$, and $12 \mathrm{mph}$ stimulus speeds in CAT performance measurements in this study. The device comprises three parts called a control console, a response button, and a runway (set; ground on which LED lights move, 2.24m) where LED lights act in a linear series (49 lamps, 1st lamp yellow colour $=$ warning lamp). The sequentially lighted LED lamps illuminate in a linear pattern with movement occurring from right to left [49]. The device was placed on a table, approximately $87 \mathrm{~cm}$ above the floor. Before the measurements started, the start and end speeds were fixed at $6 \mathrm{mph}$ and $12 \mathrm{mph}$, and the target light was determined as the 8 th lamp of the 3 sets. The warning light was adjusted with a random delay of 1 (minumum) to 2 seconds (maximum) to reduce the chance of participants predicting the test time [50]. Then, the players were invited to a quiet, calm, and low-light environment one by one. Before the actual measurement, the players were allowed to familiarize with the Bassin Anticipation Timer, necessary explanations about measurement were reminded again, and each player was given 10 trials at each stimulus speeds. After the trial measurements were completed, the players waited ready at the beginning of the device, and the signal was sent by the researcher. The players were asked to press the button using the dominant hand as close as possible to the time of arrival of the stimulus at the target location (target light) [44, 49, 50]. A total of 20 randomized measurements ( 10 for $6 \mathrm{mph}$, and 10 for $12 \mathrm{mph}$ ) were taken from each player. In addition, in 20 randomly taken measurements, the same stimulus speeds sequence was applied for both positions (offensive,

Table 1. The CAT measurements at different stimulus speeds measured randomly according to playing positions

\begin{tabular}{lllllllllll}
\hline \multirow{2}{*}{ Offensive } & $12 \mathrm{mph}$ & $12 \mathrm{mph}$ & $6 \mathrm{mph}$ & $6 \mathrm{mph}$ & $6 \mathrm{mph}$ & $12 \mathrm{mph}$ & $12 \mathrm{mph}$ & $12 \mathrm{mph}$ & $6 \mathrm{mph}$ & $6 \mathrm{mph}$ \\
& $12 \mathrm{mph}$ & $12 \mathrm{mph}$ & $12 \mathrm{mph}$ & $6 \mathrm{mph}$ & $6 \mathrm{mph}$ & $6 \mathrm{mph}$ & $6 \mathrm{mph}$ & $6 \mathrm{mph}$ & $12 \mathrm{mph}$ & $12 \mathrm{mph}$ \\
\hline \multirow{2}{*}{ Defensive } & $12 \mathrm{mph}$ & $12 \mathrm{mph}$ & $6 \mathrm{mph}$ & $6 \mathrm{mph}$ & $6 \mathrm{mph}$ & $12 \mathrm{mph}$ & $12 \mathrm{mph}$ & $12 \mathrm{mph}$ & $6 \mathrm{mph}$ & $6 \mathrm{mph}$ \\
& $12 \mathrm{mph}$ & $12 \mathrm{mph}$ & $12 \mathrm{mph}$ & $6 \mathrm{mph}$ & $6 \mathrm{mph}$ & $6 \mathrm{mph}$ & $6 \mathrm{mph}$ & $6 \mathrm{mph}$ & $12 \mathrm{mph}$ & $12 \mathrm{mph}$ \\
\hline
\end{tabular}


and defensive) to ensure the inter-position measurement standard. This same stimulus speeds sequence is shown in Table 1. The results were recorded in milliseconds according to whether the response was early or late. The raw scores from two different stimulus speeds $(6 \mathrm{mph}$ and $12 \mathrm{mph}$ ) were converted to absolute error scores. While performing CAT measurements, the players were not verbally instructed, and also were not informed about stimulus speeds order.

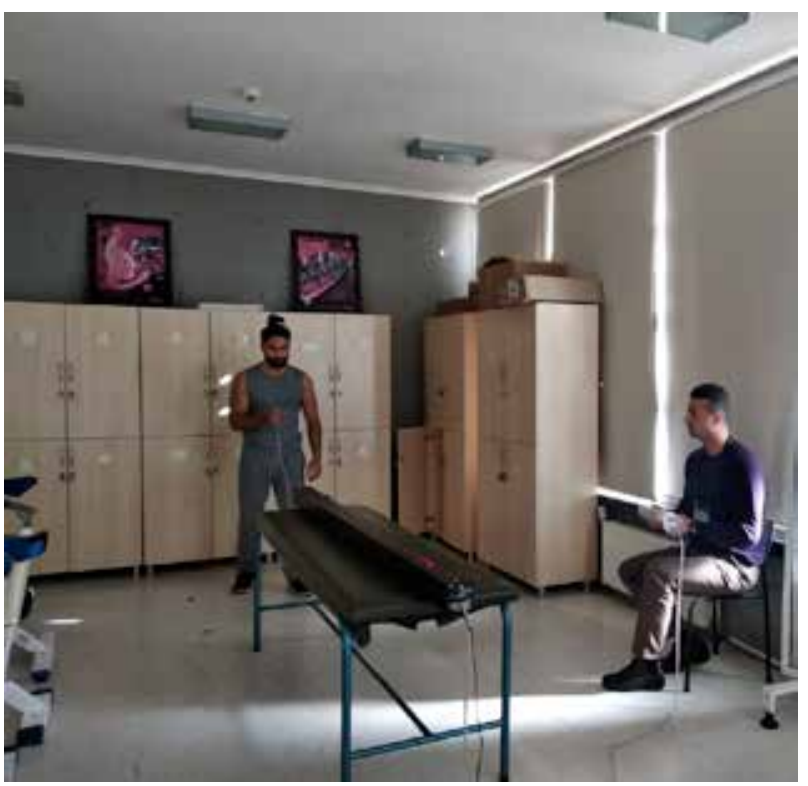

Figure 1. The CAT performance measurement

Absolute error score: It is a measure of timing error, which is frequently used in studies related to CAT performance. The absolute error gives information about the magnitude of the error made by the participant during the trial, and trial series. It also expresses the absolute value of each raw score obtained as a result of the measurement, regardless of whether the response is early or late, and explains the individual and combined effects of task characteristics as a whole. The score obtained shows the general accuracy index of an individual's performance A high score indicates that more errors were made during the trial or trials $[44,47,51]$.

Reaction time measurement: The visual (light), auditory (sound), and mixed (light or sound) reaction times of players were measured by The New Test 1000 device with a sensitivity of $0.01 \mathrm{~s}$. The Newtest 1000 device gives three stimuli, and consists of two separate parts, such as the warning device, and the warning sign for the participant to receive the warning. While, buttons 1 and 3 in black on the device provide visual, and number 2 , that is, red stimulus in the middle gives auditory (sound) stimulus. The stimula are given by the practitioner in a way that the participants can not see. The device gives values over $1 / 1000 \mathrm{sec}$. During the application phase of this research, the players were taken to a quiet, calm, and low-light environment one by one, and the device was placed on the table $10 \mathrm{~cm}$ away from the player. The players were asked to put their dominant hands on the table. Later, the researcher sent light, sound, sound or light stimuli, respectively, and players were desired to react to these stimulaas quickly as possible. Ten measurements were taken for each reaction time (visual, auditory, mixed), the highest and lowest values were not evaluated. The average of the remaining 6 measurements was used for statistical analysis [52].

Dynamic balance measurement: The dynamic balance performance of the players was designated with a portable movable balance platform Prokin Tecno Body (PKW 200 PL, Italy) with a measurement accuracy of $0.1^{\circ}$. This device is required for dynamic proprioceptive exercises (especially based on sports applications) for the lower extremities, and proprioceptive control of the trunk. The device has a small silicon chip that can detect every single angular movement with maximum accuracy. The platform has an excellent hemisphere that provides angular detection of multiple axes. The difficulty level can be changed as desired thanks to three interchangeable variable diameter discs in the system. (Easy-Medium-Hard). The system software wirelessly detects, and records every movement in real time, and provides the researcher with detailed data about the participants. Before starting the measurements, the degree of difficulty of the device was set to "medium" to measure the bi-directional dynamic balance ability. At the same time, the player was explained in detail how to perform the test. After entering the age, height, and body weight values of each player into the system, the device was calibrated. Then, player had one trial. In main measurements, the players were wanted to open their feet on the platform with their shoulders wide, and stand with their knees flexed slightly. After the foot coordinates were determined on the platform, and providing the balance on the platform, the test was initiated by the researcher in computer environment. The test was performed only once, with eyes open for each player, and consisted of trying to act in a reference circle defined by the researcher for 30 seconds. After the test was completed, three measurement values (perimeter lenght, medium equilibrium center-AP, medium equilibrium center-ML) were taken into account for statistical analysis. An increase in the perimeter length score indicates poor balance performance. The high AP and ML value indicates the weakness of quadriceps/ hamstring muscles, and the lower leg muscles in neuromuscular control during inversion and eversion movement, respectively [53].

Statistical Analysis. The data was analyzed in SPSS (20.0) program. According to the Shapiro-Wilk test results, the data showed normal distribution. Independent Sample $\mathrm{t}$ test was used to compare the CAT (6 mph, $12 \mathrm{mph}$ ), reaction time (visual, auditory, mixed), and dynamic balance performances (perimeter lenght, anterior-posterior, medial-lateral) of American football players according to their playing positions. In cases where there was a significant difference, the effect size between the two groups was calculated. Cohen's d [54] values were taken into consideration for the effect size. Significance level was accepted as $\mathrm{p}<0.05$. 


\section{Results}

Table 2. The age, height, body weight, body fat percentage and experience values of players

\begin{tabular}{llll}
\hline Variables & $\begin{array}{l}\text { Playing } \\
\text { Positions }\end{array}$ & $\mathbf{N}$ & $\mathbf{M} \pm$ S.D. \\
\hline \multirow{2}{*}{ Age (years) } & Offensive & 17 & $20.76 \pm 1.30$ \\
& Defensive & 18 & $21.94 \pm 2.87$ \\
Body Mass (kg) & Offensive & 17 & $87.15 \pm 14.24$ \\
& Defensive & 18 & $89.77 \pm 14.49$ \\
Height (m) & Offensive & 17 & $1.77 \pm .06$ \\
& Defensive & 18 & $1.80 \pm .03$ \\
Body Fat (\%) & Offensive & 17 & $17.04 \pm 6.20$ \\
& Defensive & 18 & $16.52 \pm 4.71$ \\
Experience (years) & Offensive & 17 & $2.05 \pm .82$ \\
& Defensive & 18 & $2.44 \pm 1.04$ \\
\hline
\end{tabular}

In Figure 2, absolute error scores for $6 \mathrm{mph}$ is given in milliseconds. According to the boxplot chart; When absolute error scores (6mph) of offensive (20.35 \pm 8.42 $\mathrm{ms})$, and defensive players (22.06 $\pm 7.14 \mathrm{~ms})$ were compared, there was no statistically significant difference $\left[\mathrm{t}_{(33)}=-.651, \mathrm{p}=.520\right.$, Levene's test $\left.=.854\right]$

In Figure 3, absolute error scores for $12 \mathrm{mph}$ is shown in milliseconds in the boxplot chart. As compared to defensive players $(20.15 \pm 3.81 \mathrm{~ms})$, absolute error scores (12 mph) of offensive players $(17.45 \pm 3.48 \mathrm{~ms})$ were found to be statistically significantly lower $\left[\mathrm{t}_{(33)}=-2.181, \mathrm{p}=.036\right.$, Levene's test $=.841]$. This shows that the CAT performance of offensive players was better than defensive players at fast stimulus speeds $(12 \mathrm{mph})$. Significant difference was marked with a star. The effect size for absolute error scores $(12 \mathrm{mph})$ between offensive and defensive players were determined as 0.73 . According to Cohen's d [54], the effect size was medium between two groups.

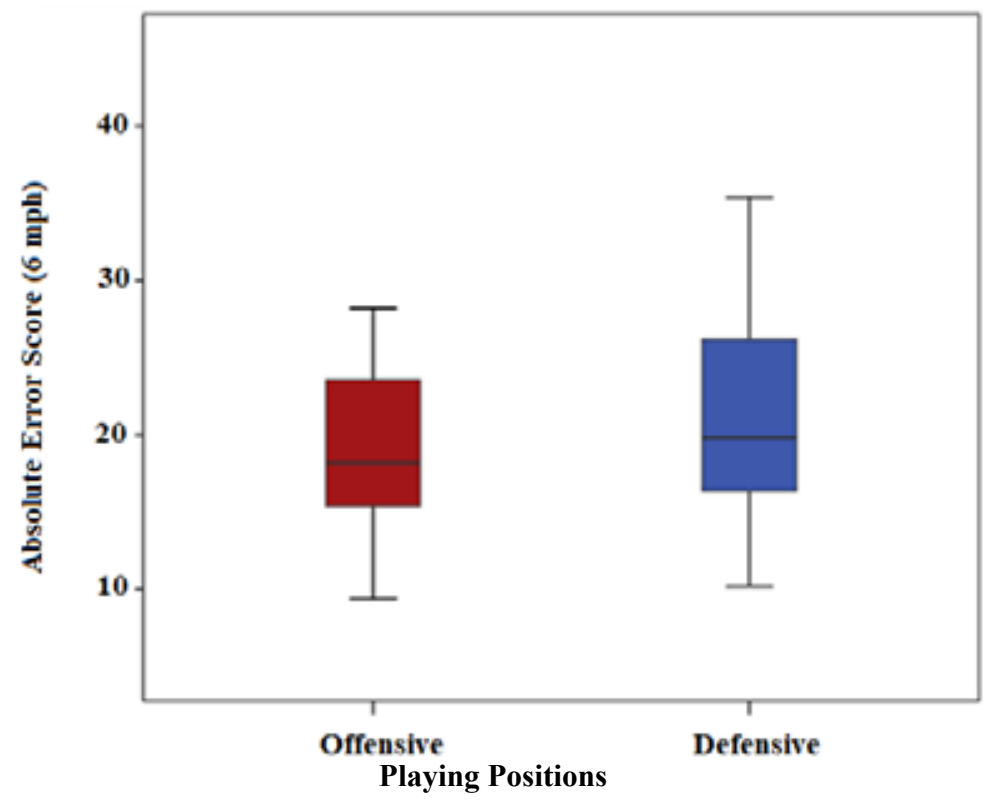

Figure 2. Comparison of Absolute Error Scores (6 mph) of American football players accroding to playing positions

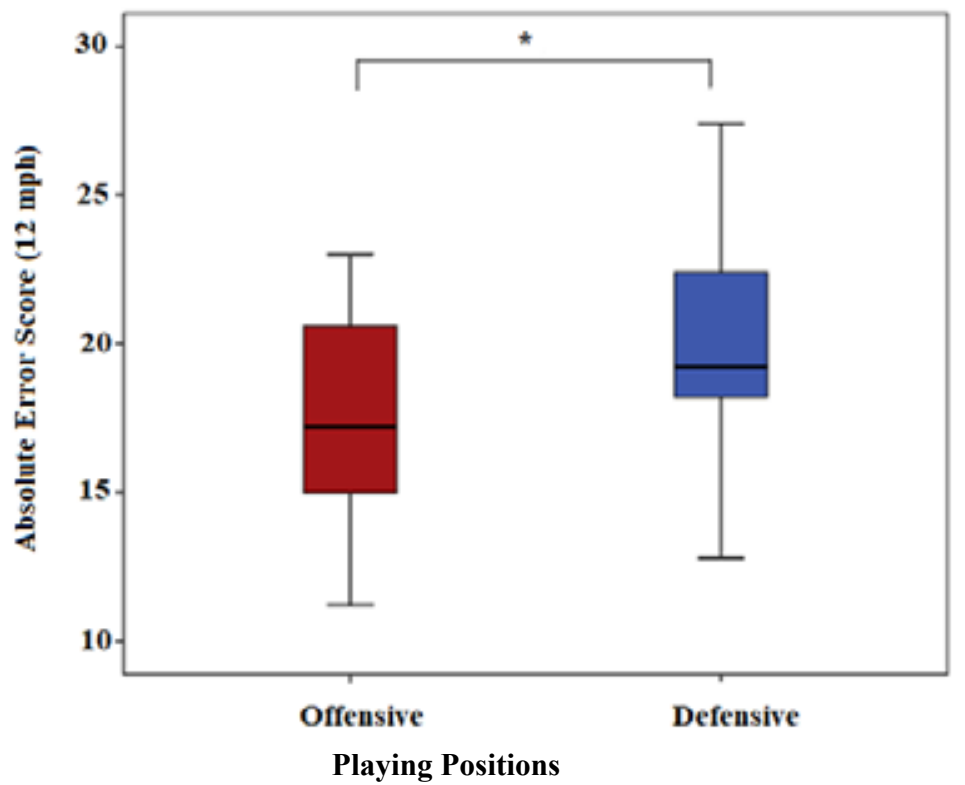

Figure 3. Comparison of Absolute Error Scores (12 mph) of players according to playing positions 
In Figure 4, the visual reaction time performance was demonstrated in milliseconds in the boxplot chart. It was found that offensive players $(318.11 \pm 17.47 \mathrm{~ms})$ had a significantly better visual reaction time than defensive players (340.58 $\pm 32.60 \mathrm{~ms})$. Significant difference was marked with a star $\left[\mathrm{t}_{(26322)}=-2.560, \mathrm{p}=.017\right.$, Levene's test $=.004]$. In terms of visual reaction time performance, the effect size between the offensive, and defensive players was 0.85 (large effect) according to Cohen's d [54].

According to Figure 5, the auditory reaction time performance was expressed in milliseconds in the boxplot chart. When the auditory reaction time of offensive $(250.30 \pm 28.38 \mathrm{~ms})$ and defensive players $(266.70 \pm 35.37$ $\mathrm{ms}$ ) were compared, a statistically significant difference was not detected $\left[\mathrm{t}_{(33)}=-1.507, \mathrm{p}=.141\right.$, Levene's test $=.181]$.

In Figure 6, the mixed reaction time performance is displayed in milliseconds in the boxplot chart. According to chart, there was no statistically significant difference between offensive (337.22 $\pm 28.92 \mathrm{~ms})$, and defensive players $(347.06 \pm 55.54 \mathrm{~ms})$ in terms of mixed reaction time $\left[\mathrm{t}_{(25899)}=-.663, \mathrm{p}=.513\right.$, Levene's test $\left.=.030\right]$.

When looking at the box-plot chart in Figure 7, there was no statistically significant difference in comparing the perimeter length of offensive $(529.06 \pm 90.77)$ and defensive $(514.65 \pm 63.09)$ players. $\left[\mathrm{t}_{(33)}=.548, \mathrm{p}=.587\right.$, Levene's test=.298]. Although not significant, it was found that dynamic balance performance of defensive players was better than offensive players.

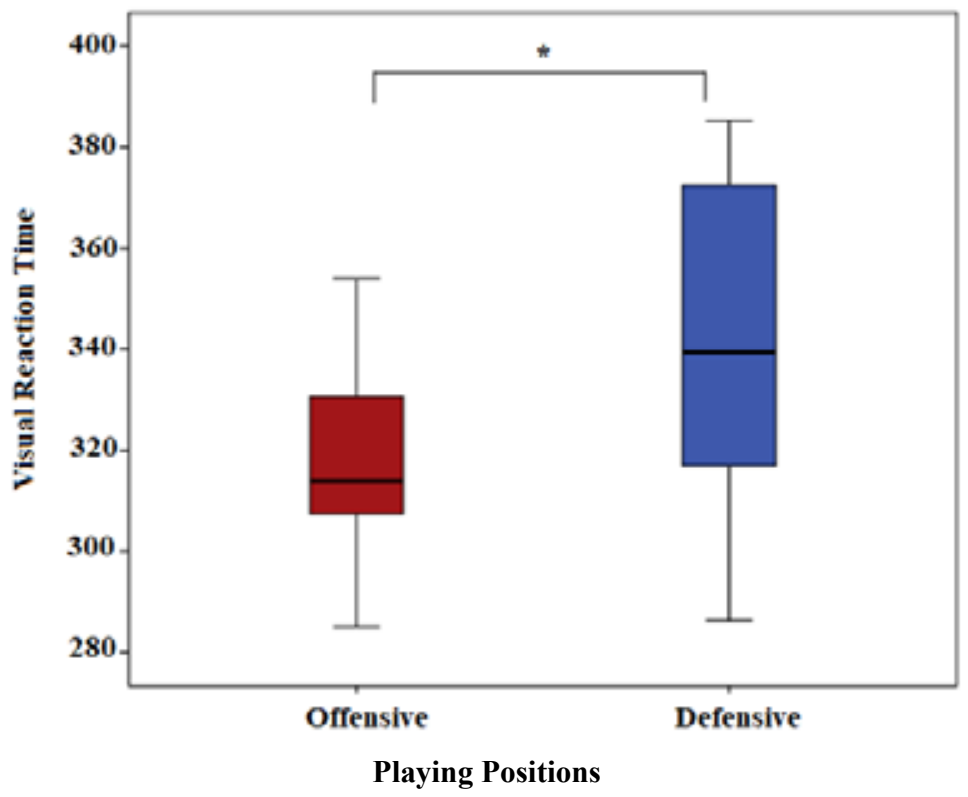

Figure 4. Comparison of Visual Reaction Time (ms) of players according to playing positions

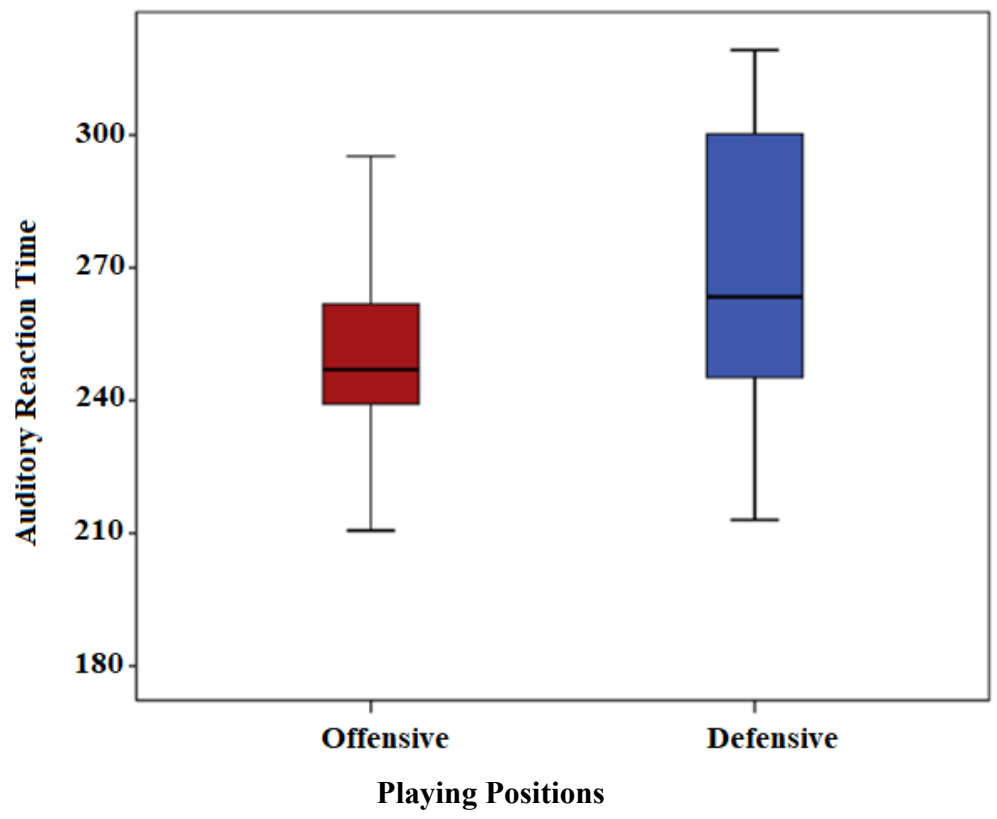

Figure 5. Comparison of Auditory Reaction Time (ms) of players according to playing positions 


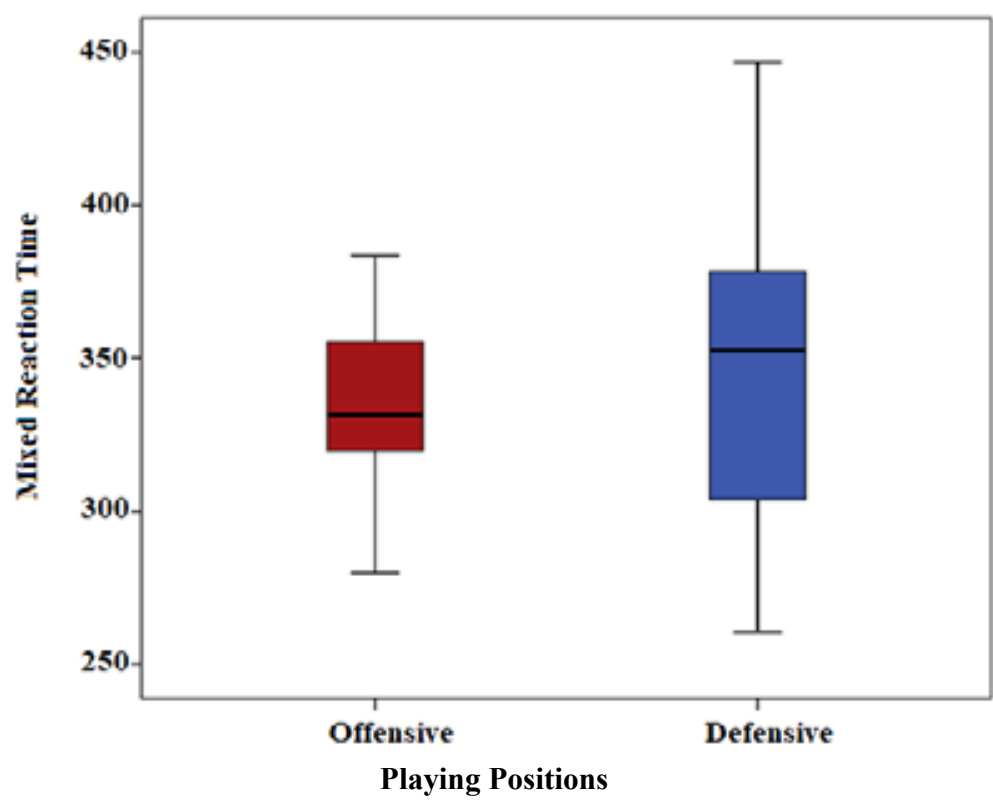

Figure 6. Comparison of Mixed Reaction Time (ms) of players according to playing positions

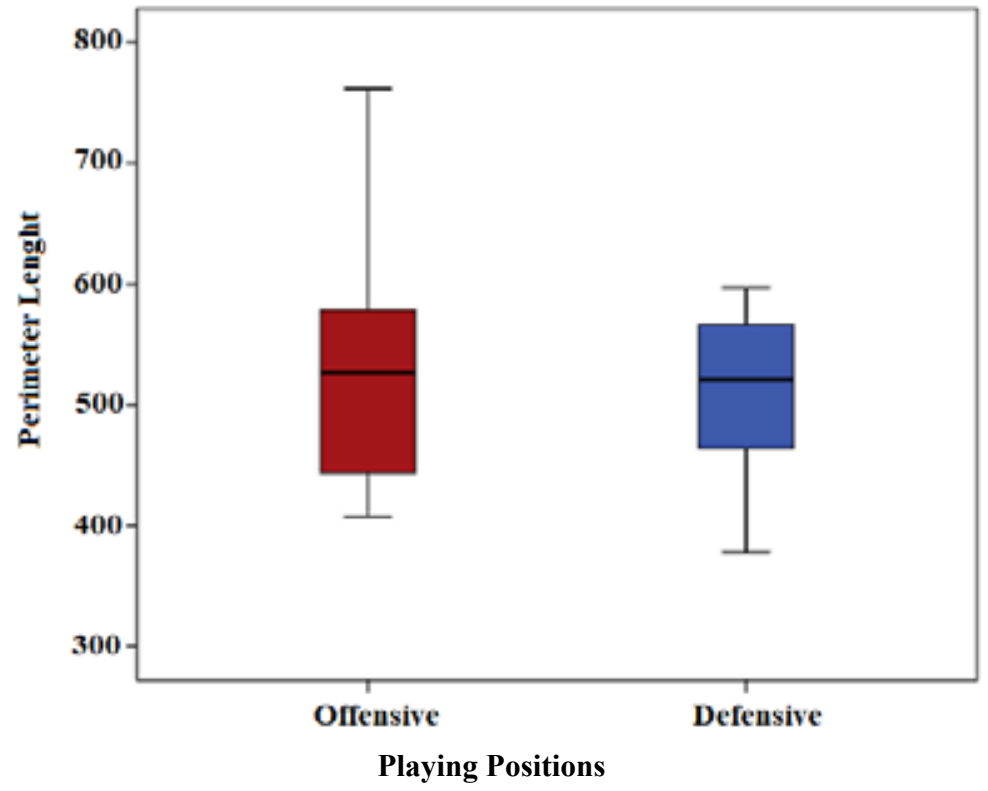

Figure 7. Comparison of Perimeter Lenght $\left({ }^{\circ}\right)$ of players according to playing positions

According to figure 8 shown in the form of a boxplot, the anterior-posterior balance performance of offensive and defensive players were found to be $-.41 \pm 2.81^{\circ},-.24 \pm$ $1.60^{\circ}$, respectively. Although not statistically significant $\left[\mathrm{t}_{(33)}=-.223, \mathrm{p}=.825\right.$, Levene's test $\left.=.056\right]$, it was observed that defensive players had better anterior-posterior balance performance than offensive players.

As shown boxplot in Figure 9, no statistically significant difference was found between offensive and defensive players in terms of comparing mediallateral balance performance. Although not statistically significant $\left[_{\mathrm{t}(33)}=1.124, \mathrm{p}=.269\right.$, Levene's test $\left.=.828\right]$, the medial-lateral balance performance of defensive players $\left(.56 \pm 1.69^{\circ}\right)$ was better than offensive players $\left(1.19 \pm 1.60^{\circ}\right)$.

\section{Discussion}

The choosing the best answer, and making the fastest response during motor actions such as catching a moving ball/object, intercepting the action of the opposing team, an attempt to prevent the passing of the ball between the two players, and hitting the moving ball/object, and their implementation at the right time through the decisions made depends on the efficiency of the decision-making processes. For this reason, CAT performance is extremely important for the timely adjustment, and synchronization of the different motor actions occurring in the game in various sports branches [55]. The accurate and successful CAT performance depends on predicting an object moving dynamically, and in a timely manner, appropriate body movements towards the object, and position of the object when the response is completed. Otherwise, biased 


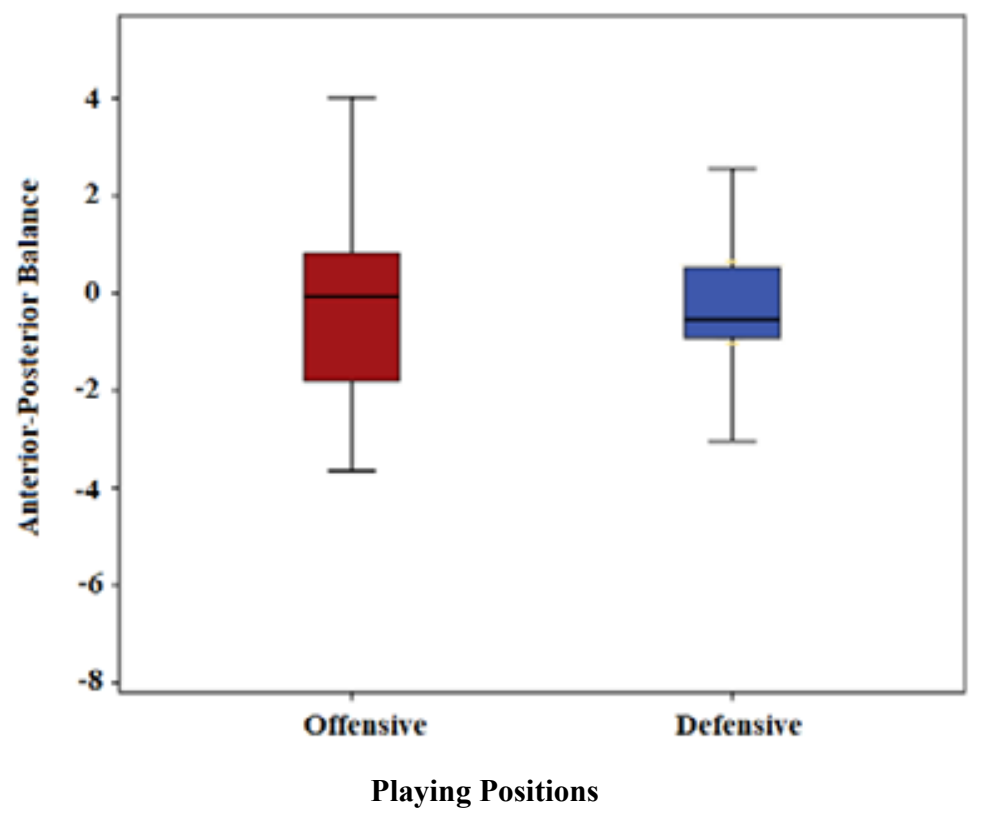

Figure 8. Comparison of Anterior-Posterior balance performance $\left(^{\circ}\right)$ of players according to playing positions

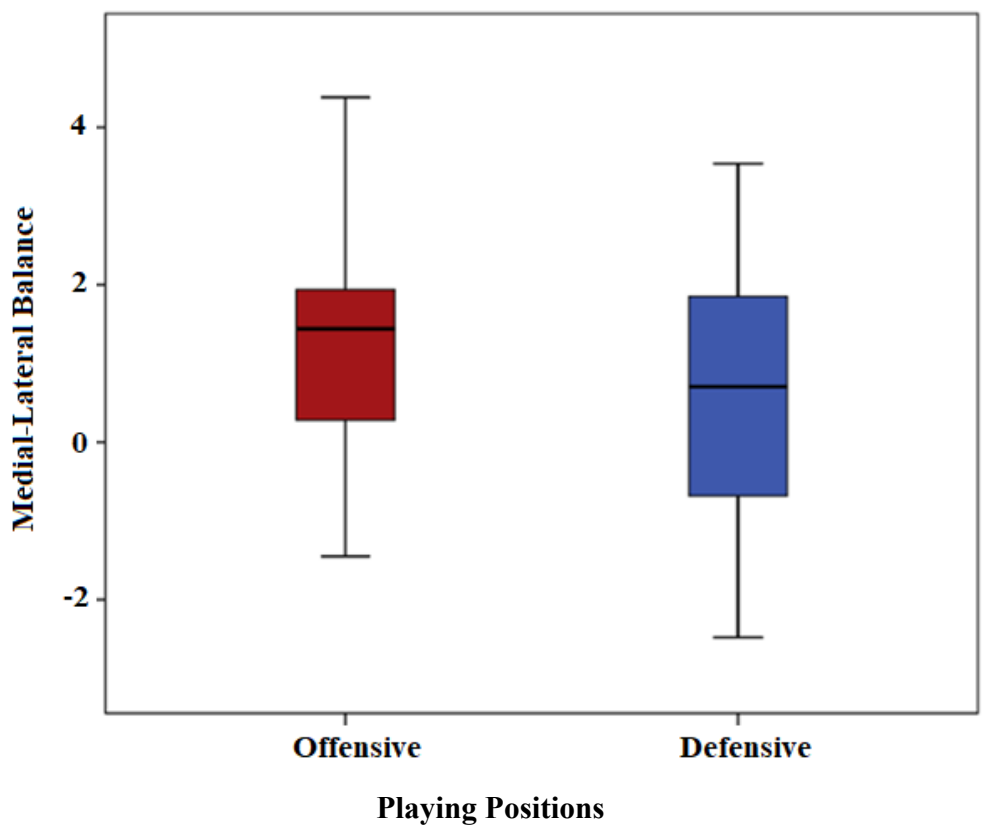

Figure 9. Comparison of Medial-Lateral Balance $\left(^{\circ}\right)$ of players according to playing positions

or wrong detection of moving object may cause temporal error [56].

Considering the results of this study, no statistically significant difference was found when the absolute error scores $(6 \mathrm{mph})$ of offensive $(20.35 \pm 8.42 \mathrm{~ms})$, and defensive $(22.06 \pm 7.14 \mathrm{~ms})$ players were compared (Figure 2). Compared to defensive players $(20.15 \pm 3.81 \mathrm{~ms})$, the absolute error score of offensive players $(17.45 \pm 3.48$ $\mathrm{ms})$ at fast stimulus speed (12 mph) were found to be significantly lower. This shows that the CAT performance of offensive players was betten than defensive players. In addition, the effect size between the two groups was found to be 0.73 . When this effect size is evaluated according to Cohen's d [54], it is at the "medium" level
(Figure 3). As compared with the low stimulus speed, the presence of a significant difference in the fast stimulus speed according to playing positions can be explained as follows; there is a relationship between the stimulus speeds, and variations in CAT performance. In a study, it was stated that the variations in response performance, ie the CAT performance, decreased as the speed of stimulus increased [48]. It has been suggested that the reason for this may be related to the information processing duration. At low stimulus speeds, the participant probably has greater difficulty in synchronizing the preparation of the action plan with the execution [57]. The participants seem to use the view as "feedback" due to the lower stimulus latency at slower speeds, and also they use their 
"conscious perceptions" that focus on stimuli, and make their responses more reflective. Conversely, the response time at fast stimulus speeds is too short to allow more informed processing of the stimulus, and participants tend to respond more automatically, and they respond in the form of "feedforward" using the subconscious perception with the automations programmed in the motor region of the brain [48].

In literature, although there are studies examining the CAT performance in different sports branches such as soccer [58], volleyball [37, 59], the studies examining the CAT performance according to the playing positions in American football are quite limited. Saygin et al. [58] reported that the CAT performance at fast stimulus speeds was found to better (not significant) especially in goalkeepers and forwards compared to other positions (defenders and midfielders). In another study, Gunay et al. [37] expressed that middle players who played for attack had better CAT performance fast stimulus speed compared to outside players who play for defense. It was also indicated that the mid-players' in-game combinations of offense, and block responsibilities played a very important role in having better predictive or CAT performance. Zhou et al. [59] determined that volleyball players playing in different positions used different strategies for visual search. Compared to other positions, they remarked that main offensive, and supporting offensive players used shorter search durations for their viewing time, which increased the accuracy of the prediction, and decision response. In addition, the high search speed in players playing in these positions was associated with high intensity of neural activation. These studies support the results of our research. In Amerikan football, each playing positions have specific responsibilities [59]. Although the games are played within a certain tactical framework, the offensive players face different positions in the game according to the defensive players. In particular, running backs make continuous, and instantaneous decisions to move the ball forward, to predict the appropriate areas in the game, to maneuver at the right time without colliding with the opponent player to prevent possible injuries, and to score points. Besides, in order to advance the ball, they have to read the block of offensive linemen correctly. At the same time, quarterbacks analyze the game from a wide angle, identify the most suitable wide receivers meet the ball at the right time to score points or cover distance. Wide receivers need to predict the opponent's movements and positions to overcome from the opponent, and move the ball as far as possible or to anticipate direction of the ball that doesn't always come at the same intensity or height to catch the ball by quarter backs. As explained above, offensive players such as quarter backs, running backs and wide receivers take multi-faceted actions in the game due to the responsibilities of the characteristic structure of the game, and their playing positions according to defensive players. This can lead to improved processing ability of the central nervous system, and positively affect CAT performance at fast stimulus speeds.

Visual reaction time is related to how quickly a player reacts to visual stimulus [46]. The reaction to actions quickly and at the right time in a dynamic environment within the game provides an advantage to the player in obtaining the desired results. According to the results of this study, the duration of auditory, and mixed reaction were found to be shorter although not significant compared to the defensive players (Figure 4 and 5), however, offensive players $(318.11 \pm 17.47 \mathrm{~ms})$ were found to have a statistically significantly superior visual reaction time than defensive players $(340.58 \pm 32.60 \mathrm{~ms})$. In terms of visual reaction time performance, the effect size between the offensive and defensive players was 0.85 (large effect) according to Cohen's d [54]. (Figure 4). The studies examining reaction time performance by playing positions in American football are limited. The study was conducted on college American football players by Wylie et al. [10] found the overall mean response speeds, and accuracies of o $\square$ ensive $(355 \mathrm{~ms}, 85.1 \%)$ and defensive $(350 \mathrm{~ms}$, $83.9 \%$ ) players. The average values of reaction speed and accuracy were found close to each other. However, although the defensive players were good at the reaction speed, the response accuracy of the offensive players was higher. We can say that when a fast response is combined with a good decision making process, the desired result is obtained. The results of this research are not in line with Wylie et al. [10] research. The reason for this may be that the sample group differs in terms of physical and perceptual-cognitive characteristics. In a study, skilled position players (quarter backs, running backs, receivers, tight ends, safeties, defensive corner backs, punters, and place kickers) were reported to have faster reaction times than non-skilled position players (quarterbacks, running backs, receivers, tight ends, safeties, defensive corner backs, punters, and place kickers), and offensive players are defined as skilled position players, and support the results of this research [24]. In addition, having fast reaction time in American football prevents possible collisions or injuries. In a study, it has been found that players with slow reaction times were slower to prepare for the collisions, and as a result they experienced higher magnitude head impacts [60]. Fujii et al. [61] notified that the players who keep the body of the opponents in the central view, and the position of the contact foot in the peripheral field of view were very likely to predict the actions of the opponents, and accordingly they reacted faster [61]. The CAT and reaction time performance are related perceptual-cognitive characteristics. Therefore, the fact that CAT performance was superior in offensive players may also have affected their visual reaction time. The offensive players such as quarter backs, running backs, and wide receviers have to communicate with each other in seconds, and need to produce extra perceptual-cognitive solutions except tactics to pass the defensive players, advance the ball or score points. In this very short period of time, in order to have a quick reaction, they necessiated to analyze the movements of the ball, each other, defensive players, and even the general characteristics of the games correctly. The challenging perceptual-cognitive demands of the game, 
and the variety of positions that they face are different in offensive players as compared with defensive players. For such reasons, the reaction time of the offensive players may be shorter than defensive players. In literature, it was propounded that short response time of the high level players to the reactions in different sports branches may be due to the functional characteristics associated with the demand of the their playing positions [38], the structural and functional characteristics of the middle temporal area sensitive to the visual movement [62], and the effect of the dynamic sensorimotor demands associated with sports on the central nervous system [63].

The dynamic balance performance is an important prerequisite for an athlete's performance and for the prevention of injury risks in sports. The deficiencies in dynamic balance can lead to body instability, overloading of musculoskeletal structures that cause dysfunction and pain [64]. Since American football is a collision-based sport, the risk of injury is very high. The dynamic balance test measurements such as The Star Excursion Balance Test, Functional Movement Screen and Y-Balance Test are common and reliable tests used to evaluate the injury risk of lower limb injury, neuromuscular control, and core stability, lower limb balance performance, and asymmetries in American football [29, 65, 66, 67]. In previous studies was shown that American football players with increased asymmetry in dynamic balance had a higher risk of contactless musculoskeletal injuries in the lower limbs [68], and contactless injuries to the knee or ankle [69]. There are a limited number of studies in the literature comparing dynamic balance performances of American football players according to their playing positions. According to the results of this study, no statistically significant difference was detected in the comparison of the dynamic balance parameters of the offensive and defensive players such as perimeter lenght, anterior-posterior, and medial-lateral. Although not significant, the dynamic balance performance of the defensive players was found to be better than the offensive players $(p>0.05)$. (Figure 5-9). This can be explained as follows; defensive players such as defenseline and linebackers try to defend by lowering their center of gravity in order to drop the offensive players or win the ball in line with the tactical understanding of their playing positions. The defensive players by constantly lowering their center of gravity may contributes to the development of their dynamic balance skills. In further studies, by increasing the sample size, repeating this study may lead to a significant difference in balance performance between playing positions. Bizid ve Paillard [70] detected that anterior posterior dynamic balance in a non-learned standardized balance task in eyes open condition differed between offensive and defensive soccer player in favor of the defensive players. They also reported that defensive players were more successful in balance tasks that require postural compensatory activities as they are more trained to respond to the attacks of offensive players, and try to tackle the opponents directly. The conclusion and interpretation of Bizid and Paillard [70] research is partially consistent with the results of this study. In another study, it was demonstrated that players who participated in contact sports like football and American football had superior postural control during difficult unipedal stance compared to players who participated in limited contact sports such as baseball. When visual information was interrupted, it was observed that contact athletes were not affected much in terms of balance, and their balance performances were not dependent on visual system. This is due to the fact that contact athletes used information from the sensorimotor, and vestibular system to maintain balance when visual information was interrupted. Since sensory systems change in environmental conditions in contact sports such as American football and soccer, it is important to improve proprioceptive and vestibular functions related to maintaining balance due to sensory re-weighting [71].

\section{Conclusions and Recommendations}

It was shown with studies that the physical and motoric characteristics of American football players were different according to their playing positions. In addition to these characteristics, the perceptual-cognitive characteristics of American football players differ when evaluated according to their playing positions. This difference was demonstrated by this study. The offensive players of CAT performance at fast stimulus speeds (12 $\mathrm{mph}$ ), and visual reaction time were found to be better as compared with defensive players. The reason for this is due to the demands of their playing position, such as the playing position of offensive players to defeat defensive players, and score points requires multi-faceted thinking in games, and to try out many different combinations of strategies in an environment with many stimuli. The CAT and reaction time are important for both offensive and defensive players. Therefore, it is considered important to include more specific exercises, video-based perceptual exercises, and visual training to improve these characteristics for both the playing positions especially defensive players in training or non-training times as well as physical training. American football is a collisionbased sport that consists of intermittent high intensity activities, so the risk of injury is very high. In order to reduce the risk of injury in the both playing positions in the games, it is recommended to measure the pre-season balance performance of players, and to plan programs for this sport-specific neuromuscular, propioceptive exercises, and dynamic balance exercises that improve the integration between the vestibular-visual system (eyes-open, eyes-closed, stable floor, and unstable floor). In the literature, Nine playing positions have been defined for American football. The offensive and defensive players are divided into positions within themselves. In the further studies, it is suggested to increase the sample size, and evaluate the CAT, reaction time, balance skills, and different perceptual-cognitive parameters (visual perception, executive function, visual control, attention, focussing etc.) taking into account all playing positions. 


\section{Acknowledgements}

We thank to Utku Sari who is a American Football Coach, helped us to perform the measurements.

\section{Conflicts of Interest}

The authors declare no conflict of interest.

\section{References}

1. Vitale JA, Caumo A, Roveda E, Montaruli A, La Torre A, Battaglini CL, et al. Physical attributes and NFL combine performance tests between Italian National League and American football players: a comparative study. Journal of StrengthandConditioningResearch.2016;30(10):2802-2808. https://doi.org/10.1519/JSC.0000000000001377

2. Ward PA, Ramsden S, Coutts AJ, Hulton AT, Drust B. Positional differences in running and nonrunning activities during elite american football training. The Journal of Strength \& Conditioning Research. 2018;32(7):2072- 2084. https://doi.org/10.1519/JSC.0000000000002294

3. Hoffman JR. The applied physiology of American football. International Journal of Sports Physiology and Performance. 2008;3(3):387- 392. https://doi.org/10.1123/ijspp.3.3.387

4. Lindon T. Examination of volume and intensities of weekday practices and competitive games in collegiate football players. [Master's Thesis]. UK: University of Kentucky; 2017.

5. Wellman AD, Coad SC, Goulet GC, McLellan CP. Quantification of accelerometer derived impacts associated with competitive games in National Collegiate Athletic Association Division I college football players. The Journal of Strength \& Conditioning Research. 2017;31(2):330- 338. https://doi.org/10.1519/JSC.0000000000001506

6. Yamashita D, Asakura M, Ito Y, Yamada S, Yamada Y. Physical characteristics and performance of Japanese top-level American football players. Journal of Strength and Conditioning Research. 2017;31(9):2455- 2461. https://doi.org/10.1519/JSC.0000000000001714

7. Pincivero DM, Bompa TO. A physiological review of American football. Sports Medicine. 1997;23(4):247-260. https://doi.org/10.2165/00007256-199723040-00004

8. Hoffman JR. Physiological demands of American football. Sports Science Exchange. 2015;28(143):1-6.

9. Robbins DW, Young WB. Positional relationships between various sprint and jump abilities in elite American football players. The Journal of Strength \& Conditioning Research. 2012;26(2):388-397. https://doi.org/10.1519/JSC.0b013e318225b5fa

10. Wylie SA, Bashore TR, Van Wouwe NC, Mason EJ, John KD, Neimat JS, et al. Exposing an "Intangible" cognitive skill among collegiate football players: enhanced interference control. Front. Psychol. 2018;9:49. https://doi.org/10.3389/fpsyg.2018.00049

11.Mori S, Ohtani Y, Jmanaka K. Reaction times and anticipatory skills of karate athletes. Human Movement

Science.2002;21(2):213-230. https://doi.org/10.1016/S0167-9457(02)00103-3

12.Pruna R, Bahdur K. Cognition in football. Journal of Novel Physiotherapies. 2016;6:316. https://doi.org/10.4172/2165-7025.1000316

13.BroglioSP,TomporowskiPD,FerraraMS.Balanceperformance with a cognitive task: a dual-task testing paradigm. Medicine \& Science in Sports \& Exercise. 2005;37(4):689-695. https://doi.org/10.1249/01.MSS.0000159019.14919.09

14.Rincon-Campos YE, Sanchez-Lopez J, LopezWalle JM, Ortiz-Jimenez $X$. Dynamics of executive functions, basic psychological needs, impulsivity, and depressive symptoms in American football players. Frontiers in Psychology, 2019;10:2409. https://doi.org/10.3389/fpsyg.2019.02409

15.Fleury M, Bard C. Age, stimulus velocity and task complexity as determiners of coincident timing behaviour. Journal of Human Movement Studies. 1985;11:305-317.

16.Runswick OR, Green R, North JS. The effects of skill-level and playing-position on the anticipation of ball-bounce in rugby union. Human Movement Science. 2020;69:102544. https://doi.org/10.1016/j.humov.2019.102544

17. Williams AM, Jackson RC. Anticipation and decision making in sport. UK: Routledge; 2019.

18.Zwierko T. Selected aspects of anticipation of soccer players. Studies in Physical Culture and Tourism. 2006;13:186-191.

19.Schmidt RA, Lee T. Motor Learning and Performance From Principles Application. 6nd. ed. USA: Human Kinetics; 2020.

20.North JS, Hope E, Williams AM. The relative importance of different perceptual-cognitive skills during anticipation. Human Movement Science. 2016;49:170-171. https://doi.org/10.1016/j.humov.2016.06.013

21.North JS, Williams AM, Hodges N, Ward P, Ericsson KA. Perceiving patterns indynamic action sequences:Investigating theprocesses underpinning stimulus recognition and anticipation skill. Applied Cognitive Psychology. 2009;23:878-894. https://doi.org/10.1002/acp.1581

22.Sors F, Murgia M, Santoro I, Prpic V, Galmonte A, Agostini T. The contribution of early auditory and visual information to the discrimination of shot power in ball sports. Psychology of Sport and Exercise. 2017;31:44-51. https://doi.org/10.1016/j.psychsport.2017.04.005

23.Atan T, Akyol P. Reaction times of different branch athletes and correlation between reaction time parameters. ProcediaSocial and Behavioral Sciences. 2014;116:2886-2889. https://doi.org/10.1016/j.sbspro.2014.01.674

24.Kalberer D, Zagelbaum A, Hersh P, Mellody J, Montgomery $\mathrm{K}$, Sison $\mathrm{CP}$, et al. Peripheral awareness and visual reaction time in professional football players in the national football League (N.F.L.). Optom.Vis.Perform. 2017;5(4):158-163.

25.Reid B, Schreiber K, Shawhan J, Stewart E, Burch R, Reimann W. Reaction time assessment for coaching defensive players in NCAA division 1 American football: A comprehensive literature review. International Journal of Industrial Ergonomics. 2020;77:102942. https://doi.org/10.1016/j.ergon.2020.102942

26. Mankowska M, Poliszczuk T, Poliszczuk D, Johne M. Visual perception and its effect on reaction time and timemovement anticipation in elite female basketball players. Polish Journal of Sport and Tourism. 2015;22(1):3-8. https://doi.org/10.1515/pjst-2015-0008

27.Sheppard JM, Young WB. Agility literature review: Classifications, training and testing. Journal of Sports Sciences. 2006;24(9):919-932. https://doi.org/10.1080/02640410500457109

28.Butler RJ, Southers C, Gorman PP, Kiesel KB, Plisky PJ. Differences in soccer players' dynamic balance across levels of competition.JournalofAthletic Training.2012;47(6):616-620. 
https://doi.org/10.4085/1062-6050-47.5.14

29.Johnston W, Duignan C, Coughlan GF, Caulfield B. Dynamic balance performance varies by position but not by age group in elite Rugby Union players-a normative study. Journal of Sports Sciences. 2019;37(11):1308-1313. https://doi.org/10.1080/02640414.2018.1557360

30.Olchowik G, Czwalik A. Effects of soccer training on body balance in young female athletes assessed using computerized dynamic posturography. Applied Sciences. 2020;10(3):1003. https://doi.org/10.3390/app10031003

31.Loughran GJ, Vulpis CT, Murphy JP, Weiner DA, Svoboda SJ, Hinton RY, et al. Incidence of knee injuries on artificial turf versus natural grass in National Collegiate Athletic Association American football: 2004-2005 through 2013-2014 seasons. The American journal of Sports Medicine. 2019;47(6):1294-1301. https://doi.org/10.1177/0363546519833925

32.KerrZY, Simon JE, Grooms DR, Roos KG, Cohen RP, Dompier TP.Epidemiology of football injuries in the National Collegiate Athletic Association, 2004-2005 to 2008-2009. Orthopaedic Journal of Sports Medicine. 2016;4(9):2325967116664500. https://doi.org/10.1177/2325967116664500

33.Severo-Silveira L, Fritsch CG, Marques VB, Dornelles MP, Baroni BM. Isokinetic performance of knee flexor and extensor muscles in American Football players from Brazil. Revista Brasileira de Cineantropometria \& Desempenho Humano. 2017;19(4):426-435. https://doi.org/10.5007/1980-0037.2017v19n4p426

34.Sterczala AJ, Flanagan SD, Looney DP, Hooper DR, Szivak TK, Comstock BA, et al. Similar hormonal stress and tissue damage in response to national collegiate athletic association division $\mathrm{i}$ football games played in two consecutive seasons. The Journal of Strength \& Conditioning Research. 2014;28(11):3234-3238. https://doi.org/10.1519/JSC.0000000000000467

35.WellmanAD,CoadSC, GouletGC,McLellanCP.Quantification of competitive game demands of NCAA division I college football players using global positioning systems. The Journal of Strength \& Conditioning Research. 2016;30(1):11-19. https://doi.org/10.1519/JSC.0000000000001206

36. Bashore TR, Ally B, van Wouwe NC, Neimat JS, van den Wildenberg WP, Wylie SA. Exposing an "Intangible" cognitive skill among collegiate football players: II. Enhanced response impulse control. Frontiers in Psychology. 2018;9:1496. https://doi.org/10.3389/fpsyg.2018.01496

37.Gunay AR, Ceylan HI., Colakogolu FF, Saygin, O. Comparison of coinciding anticipation timing and reaction time performances of adolescent female volleyball players in different playing positions. The Sport Journal. 2019;36:1-12.

38. Maciel RN, Morales AP, Barcelos JL, Nunes WJ, Azevedo MMA, Silva VF. Relation between reaction time and specific function in volleyball players. Fitness Performance Journal. 2009;8(6):395-399. https://doi.org/10.3900/fpj.8.6.395.e

39.Eken O, Ozkol MZ, Varol SR. Acute effects of different stretching and warm up protocols on some anaerobic motoric tests, flexibility and balance in junior male judokas. Pedagogy of Physical Culture and Sports. 2020;24(4):169-174. https://doi.org/10.15561/26649837.2020.0403

40.Zorba E, Saygin O. Fiziksel aktivite ve fiziksel uygunluk. Ankara: Firat Maatbacilik; 2013. (In Turkish)

41.American College of Sports Medicine. ACSM's health-related physical fitness assessment Manual. 2nd Ed. Philadelphia: Lippincott Williams \& Wilkins; 2008.

42.Dixon CB, Andreacci JL, Ledezma C. Effect of aerobic exercise on percent body fat using leg-to-leg and segmental bioelectrical impedance analysis in adults. International Journal of Body Composition Research. 2008;6:27-34. https://doi.org/10.5641/193250308X13086832906832

43.Hazir T, Acikada C. Vucut kompozisyonunun degerlendirilmesinde biyoelektrik impedans analizinin guvenirligi: karsilastirma calismasi [Reliability of bioelectrical impedance analysis in evaluating the body composition: comparison study]. Spor Bilimleri Dergisi. 2002;13:2-18. (In Turkish)

44.Boat R, Morris M, Duncan MJ. Effects of exercise intensity on anticipation timing performance during a cycling task at moderate and vigorous intensities in children aged 7-11 years. European Journal of Sport Science. 2019;1-9. https://doi.org/10.1080/17461391.2019.1642387

45.Crocetta TB, Guarnieri R, Antunes TPC, Massetti T, Abreu LCD, Fabian P, et al. Instruments for studying coincidenceanticipation timing task - An updated systematic review. Journal of Physical Education and Sports Management. 2018;5(1):37-52.

46.Kuan YM, Zuhairi NA, Manan FA, Knight VF, Omar R. Visual reaction time and visual anticipation time between athletes and non-athletes. Malaysian Journal of Public Health Medicine. 2018;1:135-141.

47. Sanders G. Sex differences in coincidenceanticipation timing (CAT): A review. Perceptual and Motor Skills. 2011;112(1):61-90. https://doi.org/10.2466/04.25.PMS.112.1.61-90

48. Rodrigues P, Lima E, Vasconcelos MO, Barreiros JM, Botelho M. Stimulus velocity effect on the performance of a coincidence-anticipation task of rightand left-handers. Revista BrasileiradeEducaçao Fisicae Esporte. 2011;25(3):487-496. https://doi.org/10.1590/S1807-55092011000300012

49.Duncan MJ, Stanley M, Smith M, Price MJ, Leddington Wright S. Coincidence anticipation timing performance during an acute bout of brisk walking in older adults: effect of stimulus speed. Neural Plasticity. 2015;210213. https://doi.org/10.1155/2015/210213

50.Duncan M, Smith M, Lyons M. The effect of exercise intensity on coincidence anticipation performance at different stimulus speeds. European Journal of Sport Science. 2013;13:559-566. https://doi.org/10.1080/17461391.2012.752039

51.Magill RA. Motor learning and control: concepts and applications. 8nd ed. New York: McGraw-Hill; 2006

52.Tamer K. Sporda fiziksel ve fizyolojik performansin olculmesi ve degerlendirilmesi [Measurement and evaluation of physical and physiological performance in sports]. Ankara: Bagirgan Yayinevi; 2000. (In Turkish)

53.Gunay AR. Adolesan donemi kadin voleybolcularda 12 haftalik proprioseptif antrenmanlarin, sezinleme zamani, reaksiyon zamani ve denge performansi uzerindeki etkileri [The effects of 12-week proprioceptive training on female volleyball players on sensing time, reaction time and balance performance]. [PhD Thesis]. Ankara: Gazi Üniversitesi; 2019. (In Turkish)

54.Cohen J. Statistical power analysis for the behavioral sciences. 2nd ed. NJ: Erlbaum;1988.

55.Rodrigues PC, Barbosa R, Carita AI, Barreiros J, Vasconcelos O. Stimulus velocity effect in a complex interceptive task in right-and left-handers. European Journal of Sport Science. 2012;12(2):130-138. https://doi.org/10.1080/17461391.2010.546059

56. Meeuwsen HJ, Goode SL, Goggin NL. Coincidenceanticipation timing. Women in Sport \& Physical Activity Journal, Reston. 1995;4(2):59-75. https://doi.org/10.1123/wspaj.4.2.59

57.Ugrinowitsch H, Correa U, Tani G. Perceptual disturbance 
and adaptive process in learning a coincident timing task. Revista Brasileira de Educação Física e Esporte. 2005;19(4):277-284.

58. Saygin O, Goral K, Ceylan HI. An examination of the coincidence anticipation performance of soccer players according to their playing positions and different stimulus speeds. Sport Journal. 2016;1-11.

59.Zhou Y. Visual search, prediction ability and brain neural mechanisms of different of female volleyball players. NeuroQuantology. 2018;16(6):512-516. https://doi.org/10.14704/nq.2018.16.6.1682

60. Weber ML, Schmidt JD, Hoffman NL. Comparing performance on baseline computerized neurocognitive and balance. $\mathrm{Br} \quad J$ Sports Med. 2017;51(11):28. https://doi.org/10.1136/bjsports-2016-097270.71

61.Fujii K, Shinya M, Yamashita D, Kouzaki M, Oda S. Anticipation by basketball defenders: an explanation based on the three-dimensional inverted pendulum model. Eur. J. Sport Sci. 2014;14(6):538-546. https://doi.org/10.1080/17461391.2013.876104

62.Hülsdünker $\mathrm{T}$, Strüder $\mathrm{HK}$, Mierau A. The athletes' visuomotor system- Cortical processes contributing to faster visuomotor reactions. European Journal of Sport Science. 2018;18(7):955-964. https://doi.org/10.1080/17461391.2018.1468484

63.Zwierko T, Osinski W, Lubinski W, Czepita D, Florkiewicz B. Speed of visual sensorimotor processes and conductivity of visual pathway in volleyball players. Journal of Human Kinetics. 2010;23:21-27. https://doi.org/10.2478/v10078-010-0003-8

64. Shirabe NA, da Silva RA, de Oliveira MR, Nowotny $\mathrm{AH}$, Sturion LA, de Oliveira Gil AW, et al. Atletas de taekwondon têm melhor controle postural do que atletas de handebol e futebol americano. Revista
Brasileira de Medicina do Esporte. 2017;23(6):473-476. https://doi.org/10.1590/1517-869220172306170049

65.Dai B, Layer J, Vertz C, Hinshaw T, Cook R, Li Y, et al. Baseline Assessments of Strength and Balance Performance and Bilateral Asymmetries in Collegiate Athletes. The Journal of Strength \& Conditioning Research. 2019;33(11):3015-3029. https://doi.org/10.1519/JSC.0000000000002687

66.Lisman P, Nadelen M, Hildebrand E, Leppert K, de la Motte S. Functional movement screen and Y-Balance test scores across levels of American football players. Biology of Sport. 2018;35(3):253-260. https://doi.org/10.5114/biolsport.2018.77825

67.Luedke LE, Geisthardt TW, Rauh MJ. Y-Balance Test performance does not determine noncontact lower quadrant injury in collegiate American Football players. Sports. 2020;8(3): 27. https://doi.org/10.3390/sports 8030027

68.Butler RJ, Lehr ME, Fink ML, Kiesel KB, Plisky PJ. Dynamic balance performance and noncontact lower extremity injury in college football players: an initial study. Sports Health. 2013;(5):417-422. https://doi.org/10.1177/1941738113498703

69.Stiffler MR, Bell DR, Sanfilippo JL, Hetzel SJ, Pickett KA, Heiderscheit BC. Star excursion balance test anterior asymmetry is associated with injury status in division I collegiate athletes. Journal of Orthopaedic \& Sports Physical Therapy. 2017;47(5):339-346. https://doi.org/10.2519/jospt.2017.6974

70.Bizid R, Paillard T. Do the soccer players' postural activities at national level of competition differ between offensive and defensive players? Science and Sport. 2006;21:23-25. https://doi.org/10.1016/j.scispo.2005.12.003

71.Liang Y, Hiley M, Kanosue K. The effect of contact sport expertise on postural control.PloSOne. 2019;14(2):e0212334. https://doi.org/10.1371/journal.pone.0212334

\section{Information about the authors:}

Halil I. Ceylan; (Corresponding Author); https://orcid.org/0000-0003-1133-5511; halil.ibrahimceylan60@gmail.com; Physical Education and Sports Teaching Deparment, Kazim Karabekir Faculty of Education, Ataturk University; Erzurum, Turkey.

Ahmet R. Günay; https://orcid.org/0000-0001-8043-6848; ahmetrahmigunay@gmail.com; Department of Training Science, Faculty of Sports Sciences, Mugla Sitki Kocman University; Mugla, Turkey.

Cite this article as:

Ceylan H, Günay A. Positional differences in anticipation timing, reaction time and dynamic balance of American football players. Pedagogy of physical culture and sports, 2020;24(5):227-239. https://doi.org/10.15561/26649837.2020.0503

This is an Open Access article distributed under the terms of the Creative Commons Attribution License, which permits unrestricted use, distribution, and reproduction in any medium, provided the original work is properly cited (http://creativecommons.org/licenses/by/4.0/deed.en).

Received: 04.03.2020

Accepted: 09.04.2020; Published: 30.10 .2020 